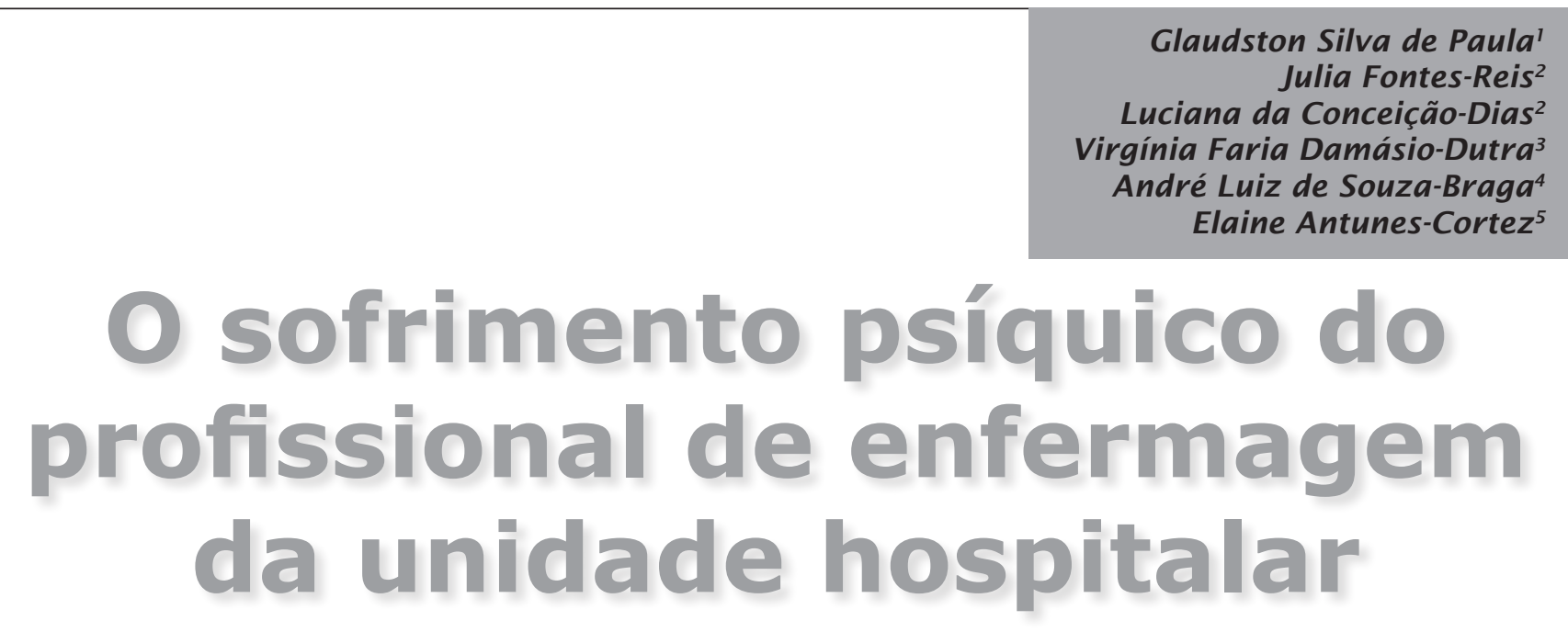

RESUMO

A equipe de enfermagem muitas vezes não percebe os problemas de saúde ao qual esta exposta. 0 objetivo do trabalho foi identificar as condições de trabalho que levam o profissional de enfermagem da unidade hospitalar ao sofrimento psíquico, para que a partir desta, possam surgir estratégias de mudanças a fim de obtermos melhoria nas condições de trabalho e consequentemente na saúde física e mental do profissional. Esta pesquisa configura-se descritiva explicativa exploratória, com uma abordagem qualiquantitativa, realizada através de pesquisa de campo, no Hospital e Maternidade Luiz Palmier, onde entrevistamos profissionais técnicos de enfermagem e enfermeiros do setor hospitalar, através de um questionário com questões abertas e fechadas. Na análise de dados, os resultados nos mostraram que o profissional em questão está satisfeito, realizado, com um a relação interpessoal satisfatória com a Chefia. 0 resultado, apesar da satisfação, aponta que a visão do profissional técnico mediante a teu superior é de maneira inadequada. Apesar dos resultados, da visão distorcida, forjada pela inexistência de conceitos como Gerência e Chefia, os profissionais atuam com o espírito da Enfermagem: 0 cuidar.

\title{
PALAVRAS-CHAVE
}

Enfermagem, saúde mental, saúde do trabalhador, estresse psicológico, ambiente de trabalho. (Fonte: DeCs, BIREME).

\section{Suffering of Psychic Training Nursing Unit Hospital}

\section{ABSTRACT}

The nursing staff often does not realize the dangers to which it is exposed. The objective of this study is to help identify elements in the work environment at hospitals that can cause psychological problems for nursing professionals and, on that basis, to facilitate strategies for changes to improve working conditions in the interest of better physical and mental health. This is an exploratory and explanatory

\footnotetext{
1 Enfermeiro. Aluno especial do Mestrado Acadêmico em Mestrado Acadêmico em Ciências do Cuidado da Saúde na Escola de Enfermagem Aurora de Afonso Costa da Universidade Federal Fluminense. Niterói, Rio de Janeiro, Brasil. glaudston.silva@bol.com.br

2 Enfermeiro graduado pelo Centro Universitário Plínio Leite, Niterói, Rio de Janeiro. juliafontes@msn.com

3 Doutoranda em Saúde Pública. Mestre em Saúde Mental. Professora do Centro Universitário Plínio Leite, Niterói, Rio de Janeiro, Brasil. virginia.damasio@gmail.com

4 Mestre em Ensino de Ciências da Saúde e do Ambiente. Professor Assistente da Escola de Enfermagem Aurora de Afonso Costa da Universidade Federal Fluminense, Niterói, Rio de Janeiro, Brasil. andre.braga@globo.com

5 Doutora em Enfermagem pela Universidade Federal do Rio de Janeiro. Professora Adjunta da Escola de Enfermagem Aurora de Afonso Costa da Universidade Federal Fluminense, Niterói, Rio de Janeiro. nanicortez@hotmail.com
}

Recibido: 24 de mayo de 2010

Aceptado: 29 de octubre de 2010 
study of a descriptive nature, with a qualitative- quantitative approach. It was conducted through field work at the Luiz Palmier Maternity Hospital, where nursing professionals were interviewed and asked to complete a standard form with open and closed questions. An analysis of the collected data showed the professionals who were interviewed are satisfied, to some degree, with the general conditions and with their superiors. However, in spite of that satisfaction, the results show technical personnel have a poor view of their superiors. Regardless of the results and the distorted view, forged by the lack of concepts such as management and leadership, professional nurses perform in keeping with the spirit of nursing, which is based on care.

\section{KEY WORDS}

Nursing, mental health, employee health, stress, psychological, working environment. (Source: DeCs, BIREME).

\section{El sufrimiento psíquico del profesional de enfermería de centros hospitalarios}

\section{RESUMEN}

El personal de enfermería a menudo no es consciente de los problemas de salud a que está expuesto. El objetivo del trabajo fue identificar las condiciones laborales en los centros hospitalarios que llevan al profesional de enfermería a sufrir enfermedades psíquicas, para que a partir de ahí, puedan surgir estrategias de cambio para mejorar las condiciones de trabajo y, en consecuencia mejorar la salud física y mental del profesional. Este estudio es descriptivo explicativo exploratorio, con un enfoque de cualicuantitativo, realizado a través de la investigación de campo en el hospital y la maternidad Luiz Palmier, donde se ha entrevistado técnicos de enfermería, enfermeros del sector hospitalário, a través de un cuestionario con cuestiones abiertas y cerradas. En el análisis de datos, los resultados mostraron que el profesional afectado está satisfecho, realizado con una relación interpersonal satisfactoria con el liderazgo. El resultado, a pesar de los puntos de satisfacción, apunta que la visión profesional técnica mediante su superior es inadecuada. A pesar de los resultados, de la visión distorsionada, forjada por la falta de conceptos tales como la gestión y liderazgo, los profesionales trabajan con el espíritu de enfermería: el cuidado.

\section{PALABRAS CLAVE}

Enfermería, salud mental, trabajador de salud, estrés psicológico, ambiente de trabajo. (Fuente: DeCs, BIREME). 


\section{Introdução}

As relações entre saúde mental e trabalho despontaram a partir da década de 1970 como marco fundamental da nova abordagem da saúde do trabalhador (1). Os profissionais mais suscetíveis aos problemas da saúde mental são aqueles que interagem, a maior parte do tempo, com indivíduos que necessitam de sua ajuda, como as enfermeiras, os professores, as assistentes sociais, entre outras profissões (2).

Com relação ao profissional de enfermagem da área hospitalar, alguns fatores interferem nas suas condições de trabalho. Entre eles encontramos o desenvolvimento rápido e contínuo da tecnologia na área da saúde; a grande variedade de procedimentos realizados; 0 aumento constante do conhecimento teórico e prático exigido nessa área; a especialidade do trabalho; a hierarquização, dificuldade de circulação de informação; 0 clima de trabalho negativo; papéis ambíguos e falta de clareza das tarefas executadas; o ritmo de trabalho, ambiente físico, estresse do contato com o paciente e familiar; a dor e a morte como elementos que potencializam a carga de trabalho ocasionando riscos à saúde física e mental dos trabalhadores do hospital $(3,4)$.

0 trabalho de enfermagem tem se apresentado como forma de prazer, mas também de sofrimento. Apresenta-se como fonte de prazer quando traz satisfação pessoal, quando o profissional desenvolve suas potencialidades humanas através de seu ofício e sente-se útil a sociedade. No entanto, quando existe submissão e repressão, o trabalho passa a ser uma mercadoria ou mero serviço prestado, podendo haver repressão das potencialidades humanas, gerando insatisfação, angústia e sofrimento psíquico.

A equipe de enfermagem muitas vezes não percebe os problemas de saúde ao qual esta exposta nem associa seus sintomas às doenças. Dificilmente a equipe de enfermagem tem idéia do que ocorre com ela, a ponto de comprometer o seu humor e seu estilo de vida, não percebendo a influência do trabalho e seu estado geral de saúde. Segundo a Organização Mundial de Saúde (5) (OMS) há um favorecimento da saúde física e mental quando 0 trabalho se adapta as condições do trabalhador e quando os riscos para a saúde estão sob controle. Na enfermagem, vive-se uma realidade de trabalho cansativo e desgastante para os trabalhadores, em que as pessoas convivem com a dor e 0 sofrimento. A alienação, a impossibilidade de agir criativamente na relação cotidiana de trabalho e os estreitos limites colocados pela organização do trabalho ao uso de seu saber surgem também como causa de sofrimento e desgaste (6).

0 objeto deste estudo foi o sofrimento psíquico do profissional de enfermagem. 0 objetivo foi identificar e caracterizar o perfil dos trabalhadores de enfermagem e as condições de trabalho que levam o profissional de enfermagem da unidade hospitalar ao sofrimento psíquico. Assim, podem surgir estratégias de mudanças a fim de obterem meIhoria em suas condições de trabalho e conseqüentemente em sua saúde física e mental.

Atualmente temos dados de pesquisa suficientes para afirmar que o cotidiano hospitalar é gerador de sofrimento psíquico para os trabalhadores da área da saúde. 0 texto de 
Pitta é marcante neste sentido, pois identifica o trabalho no hospital como penoso e insalubre para toda a equipe envolvida (7). Nosso desejo é que esta pesquisa contribua para mostrar onde há possibilidade de sofrimento psíquico no cotidiano dos profissionais de enfermagem decorrente do trabalho cansativo e desgastante onde convivem com a dor e sofrimento de outras pessoas e a partir disso possam pensar em estratégias de mudanças a fim obterem melhoria nas condições de trabalho.

\section{Metodologia}

A pesquisa é descritiva explicativa e A equipe de enfermagem muitas vezes não percebe os problemas de saúde ao qual esta exposta nem associa seus sintomas às doenças. Dificilmente a equipe de enfermagem tem idéia do que ocorre com ela, a ponto de comprometer o seu humor e seu estilo de vida, não percebendo a influência do trabalho e seu estado geral de saúde. exploratória, com abordagem qualitativa realizada através de pesquisa de campo, no Hospital e Maternidade Luiz Palmier (HMLP) em São Gonçalo (RJ) com profissionais de enfermagem do referido hospital.

0 projeto de pesquisa foi encaminhado e aprovado pelo Comitê de Ética e Pesquisa Envolvendo Seres Humanos da EEAN/HESFA (UFRJ), conforme Resolução 196/96 (CNS). Respeitando os referenciais básicos da bioética, autonomia, não maleficência, beneficência e justiça (8). Antes de iniciar a coleta dos dados, realizou-se esclarecimento sobre os objetivos gerais do estudo e os procedimentos da coleta, além de ser fornecido aos sujeitos que concordaram com a participação para assinarem o Termo de consentimento livre e esclarecido.

Quanto aos sujeitos da pesquisa, entrevistamos 40 indivíduos, 0 que representou uma amostra de $42 \%$ dos profissionais, técnicos e enfermeiros do setor hospitalar no horário diurno.
A coleta dos dados foi realizada através de um questionário com 23 questões, onde os sujeitos da pesquisa estiveram livres para responder as perguntas que Ihes convieram, e também puderam expressar suas necessidades, dar sugestões e opiniões sobre o assunto abordado.

Ressalta-se que a amostragem qualitativa privilegia os sujeitos sociais que detêm os atributos que 0 investigador pretende conhecer, pois possibilita abranger a totalidade do problema investigado em suas múltiplas dimensões (9).

De acordo com Minayo, o questionário deve ser considerado um roteiro (ou guia) facilitador de abertura, de ampliação e de aprofundamento da comunicação. Destaca ainda que as abordagens qualitativas e quantitativas não são antagônicas, mais sim complementares. Portanto é possível uma interlocução entre ambas. Além disso, o que caracteriza a diferença entre estas é a natureza dos dados coletados (10).

Quanto ao cenário da pesquisa, 0 HMLP localiza-se na cidade de São Gonçalo, que segundo o IBGE, conta como a terceira maior população do Estado do Rio de Janeiro, com aproximadamente 1 miIhão de habitantes (36). Sua população é majoritariamente de classe média. No que tange a parte física, no térreo do HMLP se localiza a emergência, ao qual não tivemos acesso por falta de disponibilidade de funcionários. No segundo andar, fica a Clínica Médica de ambos os sexos, Centro Cirúrgico, Centro de Terapia Intensiva e Unidade Coronária, já no terceiro andar localiza-se a parte administrativa do HMLP que se subdivide em administração geral e administração de enfermagem, bem como a sala de estudos de estudos. 
Para analisar os dados obtidos, adotamos os seguintes procedimentos: após a aplicação dos questionários, realizamos uma primeira leitura do material, organizamos os relatos e revimos o objetivo e questões teóricas discutidas no estudo. Terminada esta etapa, mapeamos os discursos, segundo os temas emergentes (sempre guiados pelo objetivo da pesquisa). Esses agrupamentos nos permitiram a apreensão dos significados, a associação de idéias e a captação da variedade de pensamentos. Na análise final, utilizamos os passos de Minayo (10): ordenamento dos dados, classificação dos dados e análise final. Ressalta-se que o referencial que orientou para a análise dos dados foi Dejours.

\section{Referencial teórico}

De acordo com o Ministério da Saúde (11), no Brasil a saúde do trabalhador constitui uma área da Saúde Pública que tem como objetivos a promoção e a proteção da saúde do trabalhador por meio do desenvolvimento de ações de vigilância dos riscos presentes nos ambientes e condições de trabalho, dos agravos à saúde do trabalhador e a organização e prestação da assistência aos trabalhadores, compreendendo procedimentos de diagnóstico, tratamento e reabilitação de forma integrada.

A unidade hospitalar é parte integrante de uma organização médica e social cuja função básica consiste em proporcionar assistência médica sanitária completa, tanto curativa como preventiva (12), à população. No entanto, toda assistência deve ser humanizada. Quando as conveniências da administração hospitalar e considerações econômicas pesam mais que 0 bem estar do paciente e o respeito a sua autonomia, podem acarretar a naturalização do sofrimento e a diminuição do compromisso e da responsabilidade na produção da saúde (13).

Na prática da enfermagem, o cuidado mais humano deve ser um elemento que se dá através da autenticidade, dignidade, solidariedade, afetividade e do respeito à individualidade humana (14). 0 Código de Ética dos profissionais de enfermagem (15) afirma que a enfermagem é uma profissão comprometida com a saúde do ser humano e da coletividade; atua na promoção, proteção, recuperação da saúde e reabilitação das pessoas, respeitando os preceitos éticos e legais. 0 profissional de enfermagem participa, como integrante da sociedade, das ações que visem satisfazer às necessidades de saúde da população; respeita a vida, a dignidade e os direitos da pessoa humana em todo o seu ciclo vital, sem discriminação de qualquer natureza; exerce suas atividades com justiça, competência, responsabilidade e honestidade; presta assistência a saúde visando a promoção do ser humano como um todo.

0 Sistema de Enfermagem Hospitalar é definido pela Resolução do Conselho Federal de Enfermagem (16) como um conjunto de unidades de enfermagem constituídas pelos recursos físicos e humanos em uma instituição de assistência à saúde. Os processos de atuação da enfermagem hospitalar estão inseridos diretamente nos processos assistenciais do hospital e suas ações estão relacionadas diretamente com as finalidades da instituição de saúde. Todavia, interage com os demais processos da instituição para produzir 0 efeito principal que é 0 cuidado, cuja qualidade ao final depende da eficiência, eficácia e interação deles (17).
Na prática da enfermagem, o cuidado mais humano deve ser um elemento que se dá através da autenticidade, dignidade, solidariedade, afetividade e do respeito à individualidade

humana. 
As pressões no trabalho, como o conflito de interesses e a sobrecarga, contribuem para o desequilíbrio. E o estresse não resolvido leva à deterioração da saúde mental manifestada por depressão e pela síndrome de burnout.
Os profissionais da Enfermagem Hospitalar são os responsáveis técnicos por este sistema e atuam em equipe, e ainda são os únicos profissionais dentro da instituição hospitalar, que atuam diretamente com o cliente, diuturnamente, em um trabalho contínuo e integrado. Sua ação vai além do cuidado direto ao cliente, envolvendo ainda a gerência de todas as unidades assistenciais e afins da instituição hospitalar (17).

Com essas percepções diferentes, torna-se compreensível que emirja o sofrimento psíquico (18) ao instalar-se 0 conflito entre a organização do trabalho e o funcionamento psíquico dos profissionais quando estão bloqueadas todas as possibilidades de adaptação entre a organização do trabalho e desejo dos sujeitos.

Para Dejours (19), a noção de sofrimento é central e implica um estado de luta do sujeito contra as forças que estão empurrando em direção à doença mental. E o sofrimento psíquico é uma vivência subjetiva intermediária entre a doença mental descompensada e 0 bem-estar psíquico. Neste contexto, quando o profissional é impedido de ser sujeito de seu comportamento e surgem conflitos decorrentes do confronto entre a personalidade e 0 desejo do profissional e a organização do trabalho que não lhe oferece a liberdade necessária para que possa usar suas aptidões no exercício do trabalho, culmina no sofrimento e na alienação.

As pressões no trabalho, como o conflito de interesses e a sobrecarga, contribuem para o desequilíbrio. E o estresse não resolvido leva à deterioração da saúde mental manifestada por depressão e pela síndrome de burnout (3), considerada por Harrison (20) um tipo de estresse persistente, vinculado às situações de trabalho, resultante da constante e repetitiva pressão emocional associada com intenso envolvimento com pessoas por longos períodos.

A partir das primeiras leituras que fizemos, consideramos que enquanto os profissionais não se conscientizarem dos riscos que correm e exigirem de suas chefias meIhores condições de trabalho, esse quadro não mudará e só tende a se alastrar. Fazse necessário que a chefia também tenha uma visualização do que ocorre com seus funcionários para que não se prejudique todo o trabalho de uma equipe. As chefias devem estar abertas às queixas de seus funcionários e tomar as devidas providências para que estes possam exercer de forma eficaz o seu ofício e não passem a ser cuidados ao invés de cuidadores.

\section{Resultados e discussão dos dados}

\section{Resultados}

Os dados dos 40 questionários respondidos foram organizados inicialmente em tabela, utilizando o software Microsoft Excel na versão 2003, que nos permitiu visualizar, formatar e analisar as informações coletadas que serão apresentadas. Os resultados demonstram que a equipe de Enfermagem do Hospital e Maternidade Luiz Palmier é representada por $77,5 \%$ de profissionais do sexo feminino, o que representa uma proporção de 3 mulheres para cada homem.

Ressaltamos que ao serem abordados por nós os sujeitos do estudo, observamos que $90 \%$ apresentaram relutância em contribuir com a pesquisa, sugerindo 
o vínculo contratual com a instituição em questão.

De acordo com o resultado supracitado evidencia-se a predominância do sexo feminino na equipe de enfermagem, reforçando 0 aspecto histórico da enfermagem como uma profissão feminina.

Dos entrevistados, $54 \%$ são da Clínica Médica, $10 \%$ do Centro Cirúrgico, $8 \%$ da Coronária, $8 \%$ do Centro de Tratamento Intensivo e $20 \%$ de outros setores. Destes, 24 são solteiros, 13 são casados, 1 é viúvo e 2 são divorciados. Referindo-se a patermaternidade, $50 \%$ dos entrevistados não têm filhos. No que concerne ao grau de instrução, dividem-se em dois grupos: a prevalência é o nível técnico (82\%) e 0 grupo de nível superior (18\%).

No tocante ao tempo de atividade profissional dos participantes na pesquisa, os resultados mostram que os que se agrupam até 5 anos de atuação profissional somam 23\%, de 6 a 10 anos equivale a 25\%, 11 a 15 anos unem-se em $25 \%$ e acima de 16 anos somam $27 \%$.

Sendo assim, denota-se que a maioria trabalha na Clínica Médica, são solteiros, do nível técnico e com mais de 16 anos de atuação profissional. Porém, no que tange a freqüência do tempo de atividade profissional, observa-se que está bem distribuído.

Indagados quanto ao anseio que levavam à escolha profissional, observamos que $59 \%$ dos entrevistados tiveram como fator motivacional a aptidão; $18 \%$ se referiram a "outros motivos", tais como a demanda profissional no mercado de trabalho e a facilidade de acesso pelo custo baixo; $13 \%$ chegaram ao denominador co- mum que a curiosidade foi fator preponderante na escolha e $10 \%$ direcionaram sua escolha pelas doenças familiares.

Ressalta-se desta forma que a maioria escolheu a profissão por aptidão, e a aptidão evidente sugere-nos a satisfação em fazer o que ama.

Quando abordados sob a segurança em seu trabalho relacionada à experiência prática, os que se sentem seguros totalizam $80 \%$, enquanto que o $20 \%$ restante abrange 0 grupo de inseguros. Como se observa, prevalecem os profissionais seguros com sua prática de trabalho.

Os resultados referentes à educação continuada ou permanente são 47,5\% dos entrevistados participam de programas e cursos em favor da renovação do conhecimento e 52,5\% não participam de nenhum meio em prol da atualização educacional.

É instigante, porém preocupante, o relato dos profissionais no que se refere a falta de motivação dos profissionais, devido a desunião da equipe, o descaso com a profissão e a baixa remuneração. Evidencia-se que a desunião da equipe não contribui para um ambiente salutar que se torna fator desencadeante no processo que culminará nos transtornos oriundos do estresse nos profissionais. Desta forma, as mudanças essenciais no âmbito do trabalho devem focar em estratégias para a união da equipe, valorização da profissão e melhora na remuneração.

Entretanto, os resultados também mostram que a plenitude profissional nos retorna aos primórdios da profissão, quando os sujeitos dos estudos relatam que a melhora do paciente, a realização e o altruísmo são os elementos que trazem plenitude profissional.
É instigante, porém preocupante, o relato dos profissionais no que se refere a falta de motivação dos profissionais, devido a desunião da equipe, o descaso com a profissão e a baixa remuneração. Evidencia-se que a desunião da equipe não contribui para um ambiente salutar que se torna fator desencadeante no processo que culminará nos transtornos oriundos do estresse nos profissionais. 
Não obstante as dificuldades relatadas pelos profissionais, no que tange a satisfação pessoal em relação ao trabaIho, observamos que encontram-se satisfeitos $(80 \%)$ o não satisfeitos (20\%). No cenário de realização profissional notamos que os realizados somam 65\%; e $35 \%$ encontram-se no grupo de não realizados profissionalmente em sua área atuante.

Observa-se que a maioria dos profissionais estão satisfeitos e realizados profissionalmente, mas um percentual representativo não está. Tal resultado subsidia uma intervenção junto aos profissionais não satisfeitos e não realizados profissionalmente, de forma que estes se satisfaçam e se realizem na profissão.

Quanto às questões inerentes a satisfação e a realização, nossos entrevistados dissertaram algumas justificativas, dentre as quais destacamos:

"Estou satisfeito e realizado, pois gosto do que faço" (Questionário 17).

"Realizada eu sempre fico quando eu vejo um paciente sair do hospital recuperado, apesar de não estar satisfeita com os colegas que não se unem, com a falta de recursos que temos e com a remuneração que não equivale a nossa responsabilidade" (Questionário 32).

Não obstante as notórias queixas referentes à remuneração, desunião, dentre outras, as taxas apontam que a realização e a satisfação se confirmam no âmbito de trabalho em questão.

No que concerne a relação interpessoal, 0 interagir com a chefia foi questionado. Os resultados mostram que $55 \%$ dos entrevistados mantém uma boa relação, enquanto que $45 \%$ responderam que não.
Destaca-se algumas expressões que nos direcionaram às exigências e aos paradigmas criados sob a gerência e chefia.

"É dada a oportunidade, porém eles querem da forma deles, e nem sempre eles estão corretos" (Questionário 09).

“É muito autoritarismo aqui, eles até chegam a nos ouvir, mas colocam em prática o que querem e não 0 melhor para nós" (Questionário 21).

Os entrevistados apontam 0 autoritarismo da chefia como um problema nas relações interpessoais no hospital. Tal resultado é importante, pois uma relação autoritária influencia diretamente na saúde do trabalhador de enfermagem e consequentemente no cuidado.

\section{Discussão}

Dejours (21) define o sofrimento como o espaço de luta que cobre o campo situado entre o bem-estar e a doença mental. 0 sofrimento mental pode ser concebido como a experiência subjetiva intermediária entre doença mental descompensada e o conforto (ou bem estar) psíquico (18). Cecagno e Siqueira (22) afirmam que os danos acarretados ao ser humano e seu comportamento são devidos às tensões no ambiente de trabalho, levando ao estresse profissional, conseqüente da insatisfação profissional.

Mediante 0 resultado da pesquisa, notamos que o tempo de trabalho não interfere na satisfação do trabalhador, e sim na relação direta com a equipe e chefia.

É notório que a pressão psicológica é fator desencadeante do sofrimento. Justificamos a postura aversiva dos entre-

estar) psíquico. 
vistados, pois não são respaldados, visto que sua inserção na instituição foi contratual, e o medo da perda do emprego leva à não exigência de um meio favorável, ou da participação ativa na organização do trabalho.

Sendo assim, vislumbra-se a realização da mesma pesquisa em um cenário e com sujeitos que estejam seguros, minimizando os vieses da pesquisa. Porém, é relevante a realização de outras pesquisas com sujeitos que possuam as mesmas características de forma a corroborar ou não com os resultados evidenciados e que com esses, estratégias sejam elaboradas e implementadas para a promoção da saúde deste trabalhador. Com a precarização das relações trabalhistas na área da saúde, estes profissionais representam um quantitativo expressivo nos cenários de cuidado e merecem condições dignas de trabalho.

No que concerne ao posicionamento dos sujeitos do estudo, para tentar "contorcer" ou camuflar o sofrimento, os trabalhadores usam ideologias defensivas, como deixar de tomar iniciativas e assumir responsabilidades, se fechar, não se comunicam com os outros e passam a se preocupar somente consigo, desconfiando dos colegas de trabalho que poderiam tentar prejudicá-los de alguma maneira. Assim, o relacionamento é rompido para evitar conflitos (23).

0 estudo de Graça (24) corrobora a satisfação apontada pelos entrevistados quando disserta que a satisfação no trabalho resulta da avaliação periódica que cada um de nós faz, instantaneamente e empiricamente, do grau de realização dos seus valores, necessidades, preferências e expectativas profissionais.
Os enfermeiros apontam 0 autoritarismo da chefia como um problema nas relações interpessoais no hospital. A priori cabe-nos descrever alguns conceitos necessários para 0 entendimento das divisões dos labores inerentes a cada grupo dos profissionais da enfermagem. Segundo o Dicionário Aurélio (25), chefia condiz à dignidade de chefe, repartição onde exerce suas funções, governo, direção, comando; administração significa a ação ou 0 feito de administrar, o conjunto de normas e funções que têm por fim ordenar a estrutura e funcionamento de uma organização; e gerência é a ação de gerir, assim como gestão e funções de gerente.

Posto que o conceito de gestão se confundir com o termo menos amplo administração -, convém trazer à tona a dificuldade de conceituação. A gestão se preocupa com o controle da cadeia de suprimento, o conhecimento dos clientes e os seus desejos através da pesquisa de mercado, aproximando do conceito do sistema aberto (biologia). Com relação à administração, entende que tem um foco operacional, principalmente no que tange à venda, à fabricação, à contabilidade, à engenharia e à compra. Dessa forma, se na gestão existe a preocupação com o conhecimento e os desejos dos clientes e trabalhadores, deve-se pensar que a valorização dos destes aspectos, principalmente dos trabaIhadores, possa interferir positivamente e diretamente nos cuidados.

Compreende-se que a função gerencial pode ser conceituada como um instrumento para desenhar políticas e, tecnicamente, organizar 0 processo de trabalho com o objetivo de torná-lo mais qualificado e produtivo na oferta de uma assistência, de um cuidado de enfermagem universal, igualitário e integral (26).
No que concerne ao posicionamento dos sujeitos do estudo, para tentar "contorcer" ou camuflar o sofrimento, os trabalhadores usam ideologias defensivas, como deixar de tomar iniciativas e assumir responsabilidades, se fechar, não se comunicam com os outros e passam a se preocupar somente consigo, desconfiando dos colegas de trabalho que poderiam tentar prejudicá-los de alguma maneira. 
Deste modo, a gerência pode ser encarada como um instrumento para a efetivação das políticas, pois ela pode favorecer a manutenção ou a transformação de um determinado contexto.

Na enfermagem nos dias de hoje, gerência de unidade consiste na previsão, provisão, manutenção, controle de recursos materiais e humanos para 0 funcionamento do serviço, e gerência do cuidado que consiste no diagnóstico, planejamento, execução e avaliação da assistência (26). Assim, gerenciar é cuidar, pois quando planejam, organizam, avaliam e coordenam se espera que o cuidado seja realizado da melhor forma possível (27).

Para Aguiar (28), a liderança é algo essencial no processo de trabalho gerencial do enfermeiro. Trata-se basicamente da coordenação de grupos, destacando que nas organizações, o significado atribuído à liderança, aos líderes e ao grupo reflete a filosofia, a política de pessoal e as propostas de trabalho dessas organizações. Segundo esta autora, cabe também à gerência um caráter articulador e integrativo, desde quando a ação gerencial é determinada e determinante no processo de organização de serviços de saúde e fundamenta-se na efetivação de políticas sociais e, em específico, as de saúde.

Pelos resultados, observa-se que os subordinados vêem enfermeiro chefe se distancia do papel de gerente que 0 enfermeiro tem e se limita a administrar a unidade da que é responsável. Neste ínterim, vale lembrar que a enfermagem galga o rol participativo e não supostamente designativo. No entanto, para os entrevistados a chefia tem sido um fator desmotivador, dificultador e que afasta dos princípios humanísticos proposto pelo cuidado, pois ela não tem a visão de gestão e sim de administração, ou seja, preocupa-se apenas com o foco operacional e não com o processo e o produto final, que no caso da enfermagem, é o processo de trabalho de enfermagem e o cuidado de enfermagem respectivamente.

No que concerne à distância entre 0 nível técnico e superior na enfermagem, torna-se evidente, dentro da pesquisa que a hierarquia com seus paradigmas, trazem à luz conflitos entre as subdivisões profissionais, na execução das responsabilidades cotidianas, além de conflitos nas relações interpessoais.

Os conflitos são manifestações das configurações do poder na organização; portanto, devem compreender-se nas suas formas declaradas ou silenciosas e podem ser tratados ou negados (29).

Uma estratégia a ser pensada é a inclusão da educação permanente no cenário da pesquisa. A educação permanente é crucial para o trabalhador, pois mesmo com a segurança adquirida através do tempo de trabalho, as tecnologias utilizadas em unidade hospitalar se renovam a todo instante, as condições de vida e de saúde dos usuários se modificam cotidianamente. Destaca-se que a educação permanente por ter como premissa a aprendizagem significativa, ou seja, baseada na experiência do profissional, na realidade vivenciada e na participação do profissional é benéfica para o cuidado, assim como para a relação interpessoal dos profissionais.

A educação permanente em saúde foi elaborada para aprimorar o método educacional em saúde, tendo o processo de trabalho como seu objeto de transforma- 
ção, com o intuito de melhorar a qualidade dos serviços, visando alcançar equidade no cuidado, tornando os trabalhadores mais qualificados para 0 atendimento das necessidades da população (30).

Paixão (31) nos embasa dizendo que a educação é um processo global, que não é só fornecer conhecimentos, mas desenvolvimento pleno da pessoa permitindo conhecer a realidade. Desta forma, a educação permanente não se preocupa somente com a transmissão de conhecimentos técnicos, mas também com a experiência real que 0 trabalhador vivencia e com as relações interpessoais no ambiente de trabalho, pois estas influenciam diretamente no cuidado de enfermagem.

Quando abordados quanto a motivação profissional, a prevalência rumou para a essência da profissão: o cuidar. Ou seja, a maior motivação é o próprio cuidar do outro.

Segundo Pacheco (32), a definição de cuidar abrange a prestação atenciosa e continuada de forma holística a uma pessoa enferma, realçando desta maneira 0 direito à dignidade da pessoa cuidada.

Este resultado nos leva a fonte da profissão, personificada em Florence Nightingale, que em seu imo fundamentavase nos conceitos religiosos de caridade, amor ao próximo, doação, humildade, assim como pelos preceitos de valorização do ambiente adequado para o cuidado, divisão social do trabalho em enfermagem e autoridade sobre o cuidado a ser prestado (33).

0 imo da profissão sobressai nas crises. A prevalência da essência da enfermagem, nos alerta para a satisfação do profissional. 0 mesmo culmina na plenitude da realização profissional, em fazer 0 que gosta, não obstante os dissabores e conflitos no meio.

Neste contexto, corroboramos com Damásio, Melo e Esteves (34) quando afirmam que os enfermeiros desempenham atividades de assistência direta e indireta, por meio de ações individuais e coletivas atingidas em diferentes intervenções terapêuticas visando, à autonomia e a qualidade de vida dos usuários do serviço de saúde. Deste modo, as atribuições do enfermeiro estão ligadas ao cuidado de enfermagem no âmbito individual, familiar e coletivo. Ou seja, a realização das funções de cuidar e administrar atende as necessidades do modelo clínico de assistência à saúde, que marca a enfermagem hospitalar.

A desunião dentro da equipe de enfermagem foi apontada como um problema gerador de sofrimento. Segundo Araujo, Busnardo e Marchiori (35) os profissionais chegam a este denominador comum por não abrirem mão de seus interesses pessoais para facilitar o trabalho do colega, no que se refere à carga horária de trabalho e à tarefa do cuidar. De tal modo, a equipe de enfermagem enfrenta no cotidiano do trabalho hospitalar o sofrimento gerado pelos problemas de relacionamento entre colegas, chefia e direção geral, e a dicotomia entre o cuidado humanizado que se propõem enquanto enfermeiros e a insatisfação com o vínculo e condições de trabalho. No entanto, se colocam como realizados, pois dizem gostar do que fazem e ressaltam a essência do cuidado como fator facilitador neste processo.

Por fim, evidencia-se que há uma contradição nesta análise, pois se os profis-
As atribuições do enfermeiro estão ligadas ao cuidado de enfermagem no âmbito individual, familiar e coletivo. Ou seja, a realização das funções de cuidar e administrar atende as necessidades do modelo clínico de assistência à saúde, que marca a enfermagem hospitalar. 
sionais se sentem realizados por gostarem de cuidar do outro, e se a essência do cuidado é um facilitador nesse processo, deve-se pensar em investimentos no cuidado do outro, mas do outro trabalhador, e não somente daquele que está internado, para que os mesmos mantenham essa essência de cuidar e cuidem uns dos outros, melhorando os problemas de relacionamento e minimizando a dicotomia supracitada.

\section{Considerações finais}

Na pesquisa que nos propusemos a fazer, atingimos o nosso objetivo, identificando os fatores que permitem 0 desencadear do sofrimento psíquico do profissional de enfermagem, onde nossos dados comprovam que o maior sofrimento está diretamente ligado a organização do trabalho e não com a profissão. Percebemos que o orgulho de ser enfermeiro se conflita com uma condição de trabalho insatisfatória gerada pela dificuldade de relacionamento entre os profissionais, sejam eles chefes ou colegas de trabalho.

Nossos resultados nos levam a essência da profissão, que se fundamenta no cuidar com amor ao próximo, com doação e humildade, pois a grande maioria dos entrevistados se consideram realizados e felizes em sua profissão. Desta maneira, retomamos aos primórdios da profissão, cujas bases foram erigidas por Florence Nightingale, galgadas pelo rol do altruísmo.

0 cuidado em enfermagem está diretamente ligado ao envolvimento e ao comprometimento da pessoa com a insti- tuição e com a profissão. E a produtividade deste profissional não pode ser medida por quantidade de procedimentos, pois os resultados de sua atuação nem sempre serão visíveis, palpáveis ou mensuráveis.

Os resultados também nos mostram o quanto a educação permanente é imprescindível, pois promove um ambiente saudável, visando alcançar a equidade no cuidado com propostas educativas que motivam ao autoconhecimento e aperfeiçoamento. Ademais, com a educação permanente, o cuidado não ficará limitado ao cliente, e sim a todos que participam do processo do cuidado, minimizando o sofrimento psíquico dos trabalhadores, ao pensar em estratégias de melhorias nas condições de trabalho gerada, principalmente, pela dificuldade de relacionamento entre os profissionais.

\section{REFERÊNCIAS}

1. Camarotti H, Teixeira HA. Saúde mental e trabalho: estudo da Regional Norte de Saúde do DF. Revista de Saúde do Distrito Federal (RSDF) 1996; 7(1): 29-40.

2. Baba V, Galaperin BL, Lituchy TR. Occupational mental health: A study of work-related depression among nurses in the Caribbean. International Journal of Nursing Studies. 1999; 36(1): 163-9.

3. Santos MS, Trevizan MA. Sofrimento psíquico no trabalho do enfermeiro. Nursing Rev Téc Enf 2002; 52(1): 23-28.

4. Moos RH, Cronkite RC, Finney, JW. Health and daily living form Manual. $2^{\mathrm{a}}$ ed. California: Mind Garden; 1990.

5. Brasil. Organização Mundial de Saúde (OMS). Brasília: OMS; 1985

6. Silva DMPP, Marziale MHP. Absenteísmo de trabalhadores de enfermagem em um hospital universitário. Rev latino-am Enferm 2000; 8(5): 20-33.
7. Pitta AM. Hospital: dor e morte como ofício. São Paulo: Hucitec; 1990.

8. Gil AC. Como elaborar projeto de pesquisa. $4^{\mathrm{a}}$ ed. São Paulo: Atlas; 2002.

9. Minayo MCS. Quantitativo e qualitativo em indicadores de saúde: revendo conceitos. In: Costa MFL, Souza RP. Qualidade de vida: compromisso histórico da epidemiologia. Belo Horizonte: Coopmed; 1994. p. 25-33.

10. Minayo MCS. O desafio do conhecimento: pesquisa qualitativa em Saúde. São Paulo: Hucitec; 2004.

11. Brasil. Ministério da Saúde. Portaria 1.125/GM Dispõe sobre os propósitos da política de saúde do trabalhador para o SUS. Brasília; 2005.

12. Brasil. Ministério da Saúde. Programa de Humanização da Assistência Hospitalar: Programas e Relatório 20. Brasília: MS; 2001. 
13. Pessini L, Bertachini L. Humanização e cuidados paliativos. São Paulo: Edunisc/Loyola; 2004.

14. Erdmann AL. Sistema de cuidados de enfermagem. Florianópolis: Universitária; 1996.

15. Conselho Federal de Enfermagem. Resolução Cofen 240/2000. Código de Ética dos Profissionais de Enfermagem. Cap. I. Dos princípios fundamentais. Rio de Janeiro: Cofen; 2000.

16. Conselho Federal de Enfermagem. Resolução Cofen 168/93. Normas para anotação da responsabilidade técnica de enfermeiro, em virtude de chefia de serviço de enfermagem, nos estabelecimentos das instituições e empresas públicas, privadas e filantrópicas onde é realizada assistência à saúde. Rio de Janeiro: Cofen; 1993.

17. Silva MA, Erdmann AL, Cardoso RS. O sistema de enfermagem hospitalar: visualizando o cenário das políticas gerenciais. Rev Elet Enferm 2008; 10(2): 448-59.

18. Dejours, C. A loucura do trabalho: estudo de psicopatologia do trabalho. $5^{\mathrm{a}}$ ed. São Paulo: Cortez; 1992.

19. Dejours, C. A banalização da injustiça social. Rio de Janeiro: Fundação Getúlio Vargas; 1999.

20. Harrison, BJ. Are you to burn out? Fund Raising Management. New York: McGraw-Hill; 1999.

21. Dejours, C. Uma nova visão do sofrimento humano nas organizações In: Chanlat, JF. O indivíduo na organização. $3^{a}$ ed. São Paulo: Atlas; 1996.

22. Cecagno D. Qualidade de vida e o trabalho sob a ótica do enfermeiro. Curitiba: Cogitare, 2002; 7(2): 54-9.

23. Milanesi K, Collet N, Viera CS, Oliveira BRG. Sofrimento Psíquico em Dejours. Seminário Nacional: Estado e Políticas Sociais no Brasil. Cascavel: Edunioeste. 2008

24. Graça L. A satisfação profissional dos profissionais de saúde nos centros de saúde. In: Instrumentos para a melhoria contínua da qualidade. Lisboa: Direção de Saúde; 1999. p. 1-19.
25. Ferreira ABH. Dicionário da Língua Portuguesa. Rio de Janeiro: Editora Nova Fronteira; 1980.

26. Greco RM. Ensinando a administração em enfermagem através da educação em saúde. Brasília: Rev Bras Enferm 2004; 57(4): 504-7.

27. Vaguetti H. Percepções dos enfermeiros acerca das ações administrativas em seu processo de trabalho. Brasília: Rev Bras Enferm 2004; 57(3): 316-20.

28. Aguiar AB, Costa RSB, Weirich CF, Bezerra ALQ. Gerência dos serviços de enfermagem: um estudo bibliográfico. Rev Elet Enferm 2005; 7(3): 319-27.

29. Cecílio LCO, Moreira ME. Disputa de interesses, mecanismos de controle e conflitos: a trama do poder nas organizações de saúde. Rev Adm Publ 2002; 36(4): 587-608.

30. Ceccim RB. Educação permanente: desafio ambicioso e necessário. Interface-Comunic, Saúde e Educ 2005; 9(18): 161-77.

31. Paixão W. Páginas de história da enfermagem. Rio de Janeiro: Universidade do Brasil; 1951.

32. Pacheco S. Cuidar da pessoa em fase terminal: perspectiva ética. Loures (Portugal): Editora Lusociência; 2002.

33. Padilha MICS, Mancia JR. Florence Nightingale e as irmãs de caridade: revisitando a história. Rev. Bras. Enferm. 2005; 58(6): 723-26.

34. Damásio VF, Melo VC, Esteves KB. Atribuições do enfermeiro nos serviços de saúde metal no contexto da reforma psiquiátrica. Rev Enferm UFPE. 2008; 2(4): 367-73.

35. Araújo MD, Busnardo EA, Marchiori FM. Formas de produzir saúde no trabalho hospitalar: uma intervenção em psicologia. Cad Psicol Soc Trab 2002; 5 (7): 37-49.

36. IBGE. Censo demográfico 2000. Resultados do universo. Disponível em: http://www.ibge.gov.br. Acesso em: 20 out. 2009. 